Trinity University

Digital Commons @ Trinity

Physics and Astronomy Faculty Research

Physics and Astronomy Department

2001

\title{
Energy Content of the Stormtime Ring Current
}

Niescja E. Turner

Trinity University, nturner1@trinity.edu

D N. Baker

T I. Pulkkinen

J L. Roeder

J F. Fennell

See next page for additional authors

Follow this and additional works at: https://digitalcommons.trinity.edu/physics_faculty

Part of the Astrophysics and Astronomy Commons

\section{Repository Citation}

Turner, N.E., Baker, D.N., Pulkkinen, T.I., Roeder, J.L., Fennell, J.F., \& Jordanova, V.K. (2001). Energy content in the storm time ring current. Journal of Geophysical Research: Space Physics, 106(A9), 19149-19156. doi: 10.1029/2000JA003025.

This Article is brought to you for free and open access by the Physics and Astronomy Department at Digital Commons @ Trinity. It has been accepted for inclusion in Physics and Astronomy Faculty Research by an authorized administrator of Digital Commons @ Trinity. For more information, please contact jcostanz@trinity.edu. 


\section{Authors}

Niescja E. Turner, D N. Baker, T I. Pulkkinen, J L. Roeder, J F. Fennell, and V K. Jordanova 


\title{
Energy content in the storm time ring current
}

\author{
N. E. Turner, ${ }^{1,2}$ D. N. Baker, ${ }^{2}$ T. I. Pulkkinen, ${ }^{3}$ J. L. Roeder, ${ }^{4}$ J. F. Fennell, ${ }^{4}$ \\ V. K. Jordanova, 5
}

\begin{abstract}
Given the important role the ring current plays in magnetospheric energetics, it is essential to understand its strength and evolution in disturbed times. There are currently three main methods for deducing the strength of the ring current: measuring ground magnetic perturbations, measuring high-altitude magnetic perturbations, or directly measuring ring current particles. The use of ground magnetometers is the most convenient, and many use the ground magnetometer-derived Dst index as a proxy for the ring current. Recent work suggests, however, that a substantial portion of Dst may not be caused only by the ring current but also by local induction effects or other magnetospheric currents, so simply using the Dst index may yield inaccurate results. This study uses direct particle measurements to calculate the strength of the ring current and compares this to the measured Dst values. We investigate several magnetic storm intervals, using the Polar Charge and Mass Magnetospheric Ion Composition Experiment (CAMMICE) to measure ring current ions. We then use the Dessler-Parker-Sckopke relation to compare this to the measured Dst. This analysis is used both to understand the general behavior of the ring current compared to Dst as well as to compare the usefulness of the Dst proxy for different types of storms. Ring current ions are shown in this analysis to contribute, on average, half of the Dst depression, with a large variation among individual events.
\end{abstract}

\section{Introduction}

A primary feature of a magnetic storm is a strong enhancement in the ring current. The ring current is an equatorial current around the Earth, comprised primarily of ions drifting clockwise (as viewed from above the North Pole), in the spatial range of $\sim L=2-8$ and with energies typically ranging from 20 to $200 \mathrm{keV}$ (see review of Daglis et al. [1999]). Ring current electrons drift the opposite direction around the Earth, and are of slightly lower energies, usually below $30 \mathrm{keV}$. This current decreases the strength of the Earth's dipole as measured on the surface. A system of nearequatorial ground magnetometers is used to measure the effects of the ring current and therefore to gauge the strength of magnetic storms. They produce what is known as the storm time disturbance, or $D s t$, index.

Much work has been done to measure the energy in the ring current. Hamilton et al. [1988] used particle mea-

\footnotetext{
${ }^{1}$ Now at Finnish Meteorological Institute, Helsinki, Finland.

${ }^{2}$ Laboratory for Atmospheric and Space Physics, University of Colorado, Boulder.

${ }^{3}$ Finnish Meteorological Institute, Helsinki, Finland.

${ }^{4}$ Aerospace Corporation, Los Angeles, California

${ }^{5}$ Space Science Center, University of New Hampshire, Durham, New Hampshire.
}

Copyright 2001 by the American Geophysical Union.

Paper number 2000JA003025.

0148-0227/01/2000JA003025\$09.00 surements from the Charge-Energy-Mass (CHEM) instrument on the Active Magnetospheric Particle Tracer Explorers (AMPTE)/ CCE to measure the energy density and evolution of the ring current for the major storm event which occurred in February of 1986. This storm lasted over a week and had a peak $D s t$ value of $-312 \mathrm{nT}$, which was equivalent to $-368 \mathrm{nT}$ when pressure corrected. They found $D s t$ to be well correlated with the inner ring current energy density from storm maximum well into recovery, but they did not find it to be as well correlated during the developing main phase. The local energy density multiplied by a volume estimate, assuming azimuthal symmetry, was less than but typically within a factor of 2 of $D s t$. The range of measured ring current energies throughout the event was $24-84 \%$ of the Dst variation, with an average of $51.2 \pm 17.7 \%$. The peak energy content estimated was $8 \times 10^{22} \mathrm{ergs}$, which was a factor of 14 increase from prestorm values.

Roeder et al. [1996] studied ring current ions measured by the Combined Release and Radiation Effects Satellite (CRRES). They analyzed ions from the magnetic storm event which occurred in March of 1991. They found that ring current ions could only account for 30 to $50 \%$ of the Dst variation, and they further noted that the dusk-midnight local time position of CRRES, combined with the assumption of local time asymmetry, should overestimate the total energy.

A more statistical analysis was performed by Greenspan and Hamilton [2000] also using AMPTE/CCE CHEM ion data. They studied 80 magnetic storms between 1984 and 1989 to estimate the global ring current energy. They assumed a 30\% increase in Dst due to ground currents and did 
not attempt any corrections for asymmetry, tail currents, or magnetopause currents in their data. They found a strong linear correlation between nightside ring current energy and Dst. Dayside measurements yielded essentially no correlation, which is suggestive of strong azimuthal asymmetry in the ring current. They found the highest ion densities in the nightside and the lowest in the morning sector, consistent with an ion population injected on the nightside which must drift and incur losses before reaching the morning sector. They calculated ratios of total ring current ion energy to $D s t$ for each local time sector and found a ratio of $1.4 \times 10^{29}$ $\mathrm{keV} \mathrm{nT}^{-1}$ in the $0600-1200 \mathrm{LT}$ sector and $2.2 \times 10^{29} \mathrm{keV}$ $\mathrm{nT}^{-1}$ in the $1800-2400 \mathrm{LT}$ sector. The authors speculated that given the good agreement they found between nightside ion measurements and Dst, perhaps some of the neglected effects (e.g., tail currents and magnetopause currents) might compensate for one another.

A. M. Jorgensen et al., (A statistical study of the global structure of the ring current, submitted to Journal of Geophysical Research, 2000) conducted a study of the global structure of the ring current using magnetic field data from CRRES. They derived an average magnetic field configuration of the inner magnetosphere ring current region as a function of Dst. They sorted CRRES magnetic field data by local time and global magnetic activity (Dst) to produce magnetic field maps, from which they calculated local current systems. From these current maps they determined that the ring current was asymmetric for all values of $D s t$. The peak was in the afternoon sector for quiet times and near midnight during disturbed conditions. By integrating magnetic perturbations due to the ring current, the authors were able to recreate Dst. They found the best match when assuming a perfectly conducting Earth (which would cause induced ground currents to increase the external current system contribution to $D s t$ by $50 \%$ ) and applying a $20 \mathrm{nT}$ offset to $D s t$, which they interpreted as a quiet time ring current baseline.

The present study continues and improves on the earlier works by examining data from the Polar Charge And Mass Magnetospheric Ion Composition Experiment (CAMMICE) and including the effects of other known current systems on Dst, as well as investigating and, in some cases, making corrections for ring current azimuthal asymmetry.

\section{Instrumentation and Method}

For this study, ion data from the Magnetospheric Ion Composition Sensor (MICS) instrument from CAMMICE, on board the Polar spacecraft, were used. The MICS sensor uses an ellipse-shaped electrostatic analyzer, a secondaryelectron generation/detection system, and a solid state detector to measure the energy, time of flight, and energy per charge of the incident ion flux. These three parameters permit a unique determination of the ion charge state, mass, and incident energy over the energy range from 6 to $400 \mathrm{keV} \mathrm{e}^{-1}$ [Wilken et al., 1992].

The data used in this study are from March of 1996 through September of 1998. The number of passes of Polar through

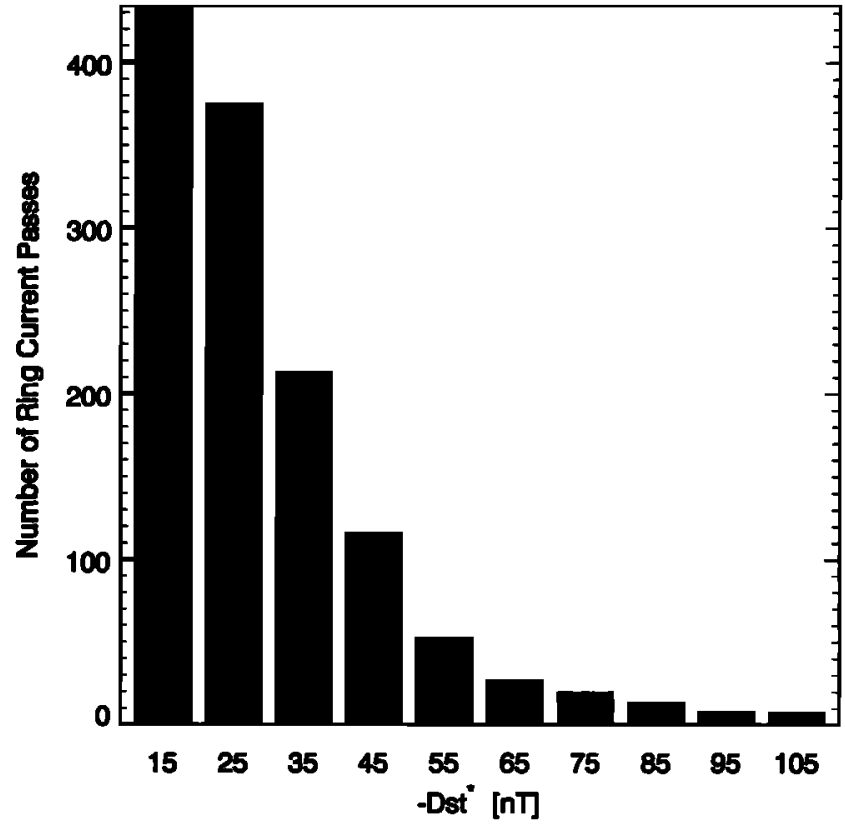

Figure 1. Number of passes of the Polar satellite through the ring current for different values of $-D s t^{*}$ Each bin has a width of $10 \mathrm{nT}$, centered on the value shown below the bar.

the ring current for different values of pressure-corrected $D s t$ is shown in Figure 1.

To calculate the energy in the ring current, energy density is calculated as a function of $L$ for each pass of the satellite. At each energy the measured local 5-min pitch angle distribution is converted to equatorial pitch angle distribution using the ratio of measured $B$ to the model equatorial B. The International Geomagnetic Reference Field (IGRF) field (no external) model is used for this due to the limited activity range required for the Tsyganenko models. Once the pitch angle distribution is mapped to the equator, it is fit to $\sin ^{n}$. The energy densities are then integrated from this equatorial spectrum. The energy density is then multiplied by the volume contained in each thin $L$ shell using (1) and summed. The volume in the Earth's dipole up to a given $L$ is calculated by

$$
\begin{aligned}
\mathrm{V}(L)= & V_{E}\left[L ^ { 3 } \sqrt { 1 - \frac { 1 } { L } } \left(\frac{0.43}{L^{3}}+\frac{0.171}{L^{2}}+\frac{0.229}{L}\right.\right. \\
& \left.+0.457)-\sqrt{1-\frac{1}{L}}\right]
\end{aligned}
$$

where $V_{E}$ is the volume of the Earth, $1.08 \times 10^{21} \mathrm{~m}^{3}$, and the resulting volume is in SI units, Lyons and Williams [1984, p. $8]$.

\section{Dessler-Parker-Sckopke Relation}

The standard assumption is that $D s t$, once corrected for the influence of other current systems, is a reliable measure of the energy content in the extraterrestrial ring current particle population. The original relationship between $D s t$ 
and the energy of the ring current particles was derived by DesslerandParker [1959] and later generalized by Sckopke [1966]:

$$
\Delta B_{\text {particles }}=-\frac{\mu_{0}}{2 \pi} \frac{W_{\text {particles }}}{B_{0} R_{E}^{3}},
$$

where $\Delta B_{\text {particles }}$ is the magnetic perturbation at the center of the Earth due to the particles, $R_{E}$ is an Earth radius (6372 $\mathrm{km}), \mu_{0}$ is the permeability of free space, $B_{0}$ is the surface dipole strength at the equator, and $W_{\text {particles }}$ is the energy in the ring current particles.

\section{Corrections to the Dst Index}

When using Dst to estimate a physical quantity such as the ring current, it is very important to understand the physical meaning of the index. Some researchers [e.g., Campbell, 1996] have strongly cautioned about its physical derivation and interpretation. Arykov and Maltsev [1996] have argued recently that tail currents can dominate Dst development during storms. Other researchers [e.g., Hamilton, 1988; Kozyra et al., 1997; Jordanova et al., 1998a; Greenspan and Hamilton, 2000] argue that ring current ions contribute the majority of the Dst depression during storms. Given the use of $D s t$ and its time variations to estimate ring current energy dissipation during storms, it is important to bracket uncertainty in the index's meaning.

\subsection{Ground Current Correction}

Effects due to induced currents in the ground were first discussed by Dessler and Parker [1959], who calculated that in a perfectly conducting planet, ground currents would enhance $D s t$ by $50 \%$ and more realistic conductivity values would cause a smaller influence. Later work by Langel and Estes [1985] indicates that the ground currents in the Earth are $29 \%$ of the external currents at dawn and $24 \%$ at dusk, suggesting that induced currents would likely increase the magnitude of the Dst depression between 24 and $29 \%$. Note that these percentages represent the fraction of the external currents, not the fraction of Dst. The internal and external currents are superposed in any ground magnetometer measurement. Assuming the average induced ground currents enhance Dst by $26.5 \%$, the removal of such an effect would require a reduction of $21 \%$ of the measured $D s t$.

\subsection{Magnetopause Current Correction}

Magnetopause currents have also been shown to contribute to the field perturbation felt on Earth. Burton et al. [1975] proposed the following formula to remove the magnetopause current contribution from the measured $D s t$ :

$$
D s t^{*}=D s t-b \sqrt{P}+c,
$$

where $P$ is the solar wind dynamic pressure, $b$ and $c$ are constants, and $D s t^{*}$ is the so-called pressure-corrected $D s t$.

For this study, the pressure correction was calculated using Burton et al.'s [1975] equation, setting the constants $b=8.74 \mathrm{nT}(\mathrm{nPa})^{-\frac{1}{2}}$ and $c=11.54 \mathrm{nT}$. The use of more recently derived constants, namely those calculated by $O^{\prime} B r i e n$ and McPherron, [2000] (where $b=7.26$ and $c=11.0$ ), made no difference in the overall result.

\subsection{Tail Current Correction}

Turner et al. [2000] assessed the effects of the tail current system on Dst using modified versions of Tsyganenko's $[1989,1996]$ models. They used the models to calculate the tail currents and then subtracted their effect from the modelderived Dst index. On the basis of this analysis, they concluded that for the small storms (Dst $>-100 \mathrm{nT}$ ) modeled, the tail current contribution to Dst was around $25 \%$. Since their modeling was done in most cases at the end of the growth phase of storm time substorms, when the tail currents would be most dominant, the $25 \%$ correction factor may be a slight overcorrection for other times.

\subsection{Total Adjustments to Dst}

For all events in this study, Dst has been pressure corrected using (3) in order to remove the effects of magnetopause currents. Additionally, the ring current energy has been scaled to an "equivalent $D s t^{*}$ " by first dividing by the Dessler-Parker-Sckopke (DPS) relationship constants (see (2)) and then subtracting $21 \%$ for induced ground currents and another $25 \%$ for magnetotail currents. In other words, the ring current energy is scaled to 54\% of the DPS-predicted Dst value in order to compare it with the measured (and pressure corrected) $D s t$.

\section{Ring Current Asymmetry}

\subsection{Asymmetry Data}

The ring current is known to exhibit local time asymmetry during disturbed times. This asymmetry was studied

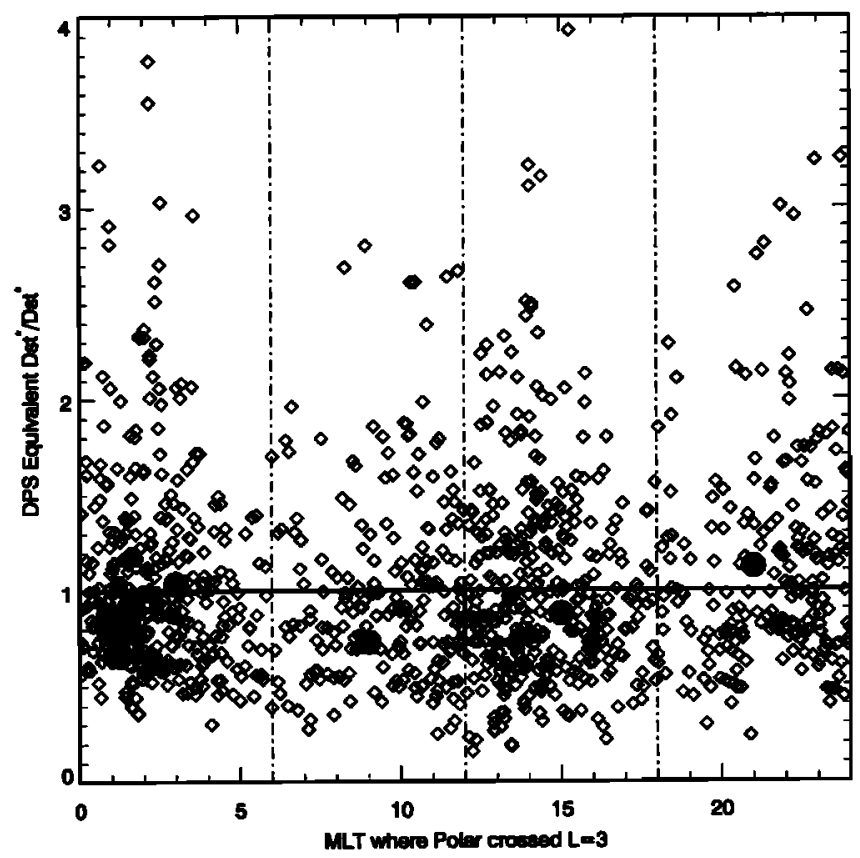

Figure 2. Ring current energy normalized by $-D s t^{*}$ for all events versus magnetic local time (MLT). Filled circles indicate average values shown for storm time passes, i.e., $D_{s t}{ }^{*}<-50 \mathrm{nT}$. They do not represent averages of all points shown in Figure 2. (DPS = Dessler-Parker-Sckopke). 

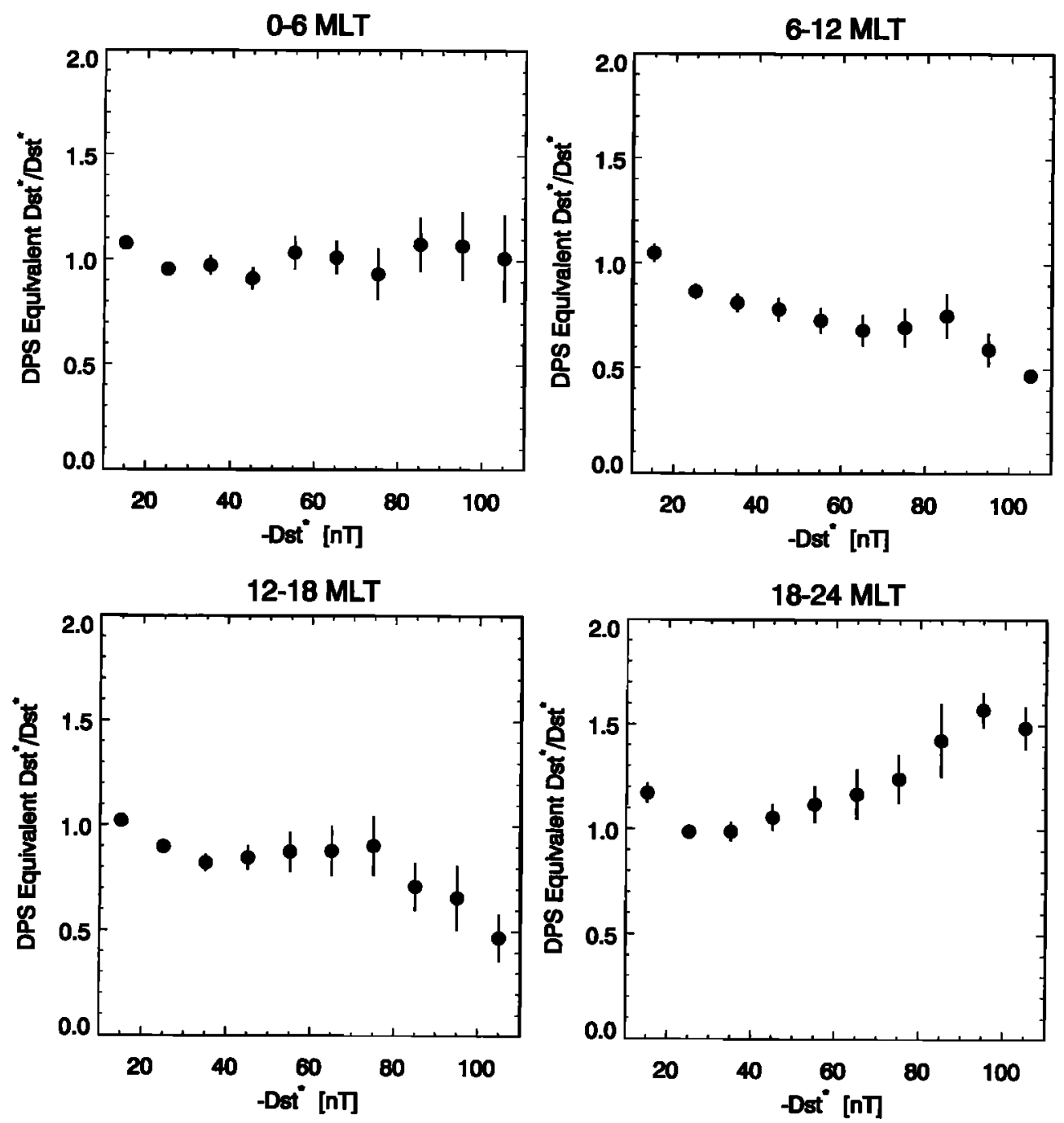

Figure 3. Ring current asymmetry shown as a function of $D s t^{*}$. The filled circles show the ratio of measured ring current energy and $D s t^{*}$, where ring current energy is scaled by the DPS relation, corrected as described in the text. Each bin has a width of $10 \mathrm{nT}$. The error bars show the standard deviation of the mean for each bin.

by Greenspan and Hamilton [2000], as described in section 1. Their analysis showed the morning sector particles contributing the least to $D s t$ and the evening sector contributing the most. Analysis with Polar data confirms this finding, as well as offers another. Figure 2 shows Polar/CAMMICE data for all passes versus magnetic local time (MLT). The energy from each pass is scaled to an equivalent $D s t^{*}$ value by using (2) and applying tail and ground corrections as described above, and then dividing by $D s t^{*}$. The points in Figure 2 deviate from the predicted values in all local time sectors. This could be due to Polar's location (azimuthal asymmetry), magnetospheric activity level, or simply a large variety in ring current responses. Averages in each MLT sector were taken only from those points corresponding to $\mathrm{Dst}^{*}$ of less than $-50 \mathrm{nT}$, not the entire data set.

To help account for the large variation evident in Figure 2 , data were also sorted by magnetic activity level (as defined by $D s t^{*}$ ) in addition to MLT, as shown in Figure 3.
This analysis shows that the degree of measured asymmetry varies with geomagnetic activity. For each MLT sector, all available passes of Polar data were binned according to the value of $D_{s t}{ }^{*}$, and in each case the ring current energy was scaled to equivalent $D s t^{*}$ with the DPS relation, including corrections for ground and tail currents. These values were then divided by the appropriate $D s t^{*}$ value, so they show each sector's relative contribution to $D_{s t}{ }^{*}$. A value close to 1 indicates an average contribution to $D s^{*}$, while a large value indicates a disproportionately large contribution, and a value less than 1 corresponds to a smaller relative contribution. These data show that the evening sector becomes increasingly more important during times of large geomagnetic disturbances, while the morning and afternoon sectors become less important. This is consistent with particles being injected from the nightside rapidly during geomagnetically active times and then drifting around the Earth, incurring losses along the way. This analysis did not separate 

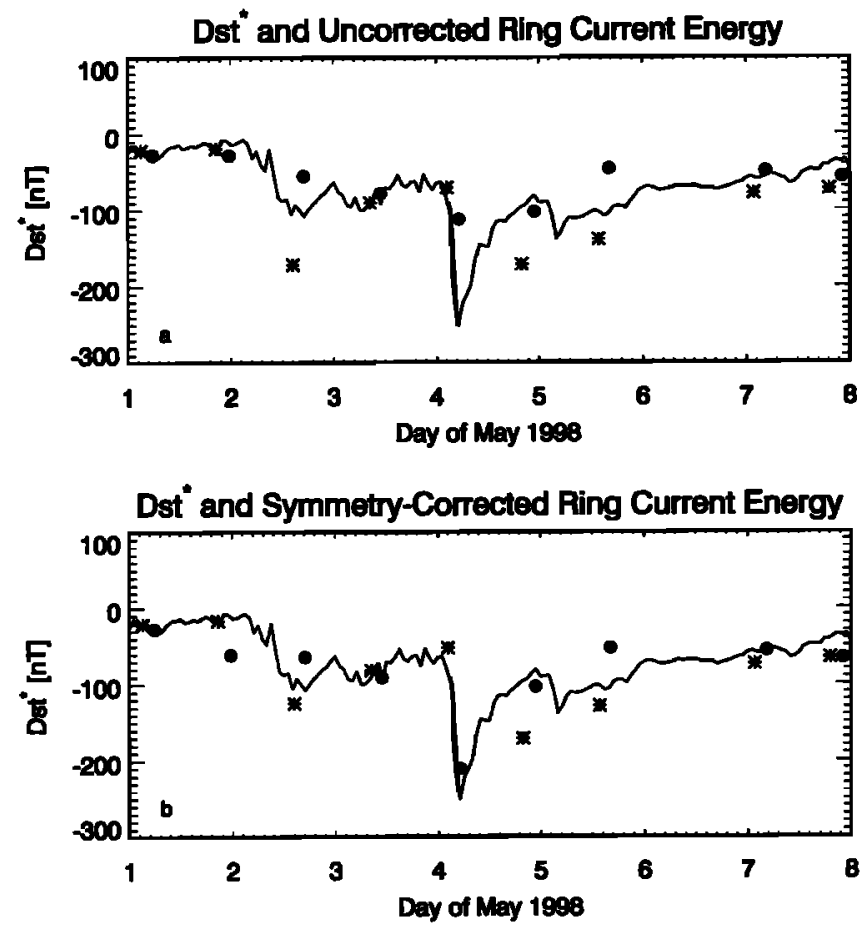

Figure 4. May 1998 storm event: (a) $D s t^{*}$ and ring current energy, corrected for magnetopause, tail, and ground currents. Filled circles indicate dayside passes (around 1000 MLT), and asterisks indicate nightside passes (around 2200 MLT). (b) same as (a), but also corrected for azimuthal asymmetry using Jordanova et al.'s [1998b] model-derived correction.

main phase versus recovery due to the limited size of the data set for periods of high activity. The late-night sector (0000 - $0600 \mathrm{MLT}$ ) seems to maintain a steadier value relative to $D s t^{*}$, which indicates that particle measurements in this sector correlate better with $D s t$ than do measurements from other locations.

\subsection{Model-Derived Asymmetry Correction}

Figure 4 shows the $D s t^{*}$ index for the May 1998 storm [see also Baker et al., 2001], along with the total ring current energy for each pass of the Polar satellite. For the purposes of comparing ring current energy with $D s{ }^{*}$, the ring current energy was converted into equivalent $D s t^{*}$ by applying the DPS relation and correcting for ground and tail currents as described in section 4. Filled circles indicate dayside passes (around $1000 \mathrm{MLT}$ ), and asterisks indicate nightside passes (around 2200 MLT). Figure 4a shows ring current energy values for which no asymmetry correction has been ap- plied. For all passes in Figure 4b, a model-derived asymmetry correction has been applied to help correct for the azimuthal asymmetry of the ring current. The model used was that of Jordanovaetal. [1998b], which follows the evolution of three major ring current ion species $\left(\mathrm{H}^{+}, \mathrm{He}^{+}\right.$, and $\left.\mathrm{O}^{+}\right)$ considering adiabatic drift motion and losses due to charge exchange with the hydrogen geocorona and Coulomb collisions with a time-dependent plasmasphere. The model was driven by a $K \boldsymbol{p}$-dependent Volland-Stern convection electric field, and time-dependent magnetospheric inflow on the nightside boundary, inferred from geosynchronous Los Alamos National Laboratory (LANL) observations during May 2-8, 1998. A free outflow of ring current ions from the dayside boundary was allowed to take into account losses through the dayside magnetopause.

The model was used to simulate ring current development during the May 1998 storm period. The percentage of energy density for each species as a function of time and MLT was calculated, and each Polar data point was corrected according to these calculations. These corrected data show a very strong ring current response to the solar wind conditions. On May 2, the ring current underwent its first intensification, corresponding to a Dst of around -100 nT. The second, larger intensification resulted in a $D s t^{*}$ value of $250 \mathrm{nT}$. The ring current energy at the peak of the storm was $\sim 4 \times 10^{15} \mathrm{~J}$. Generally, the data show a reasonably good agreement between $D s t^{*}$ and the measured ring current energy. The largest discrepancies occur in the early recovery phase, where the nightside passes are enhanced relative to the dayside passes. This indicates that the data show a stronger asymmetry than the model does, and thus are not adequately corrected. For the rest of the storm, the modelcorrected data appear to be consistent both with other data points from different regions and with the $D s t^{*}$ index. Figure 5 shows another view of the same event. Again, the top panel (Figure 5a) is uncorrected, and the bottom panel (Figure $5 b$ ) has been adjusted to account for asymmetry. The line $Y=X$ is shown to guide the eye. From this view it is clear that the largest corrections were during times of higher activity, and generally the data correlate more highly in Figure 5b than in Figure 5a. The linear correlation coefficient in Figure $5 \mathrm{a}$ is $\mathbf{0 . 7 8}$, and the linear correlation coefficient in Figure $5 b$ is 0.88 .

\section{Statistical Results}

Statistics for all events from March of 1996 through September of 1998 are shown in Table 1 . The first column shows the peak value for $-D s t^{*}$, followed by the percentage of $D s t^{*}$

Table 1. Ring Current Correlations With $D s t^{*}$, Shown for all Events in the Study

\begin{tabular}{lccccc}
\hline$-D s t^{*} \geq$ & Percent of $D s t^{*}$ & Std. Dev. & Overall Correlation & Dayside & Nightside \\
\hline $20 \mathrm{nT}$ & $48 \%$ & $\pm 25 \%$ & .65 & .57 & .74 \\
$50 \mathrm{nT}$ & $51 \%$ & $\pm 27 \%$ & .42 & .37 & .56 \\
$70 \mathrm{nT}$ & $52 \%$ & $\pm 27 \%$ & .23 & .17 & .42 \\
\hline
\end{tabular}



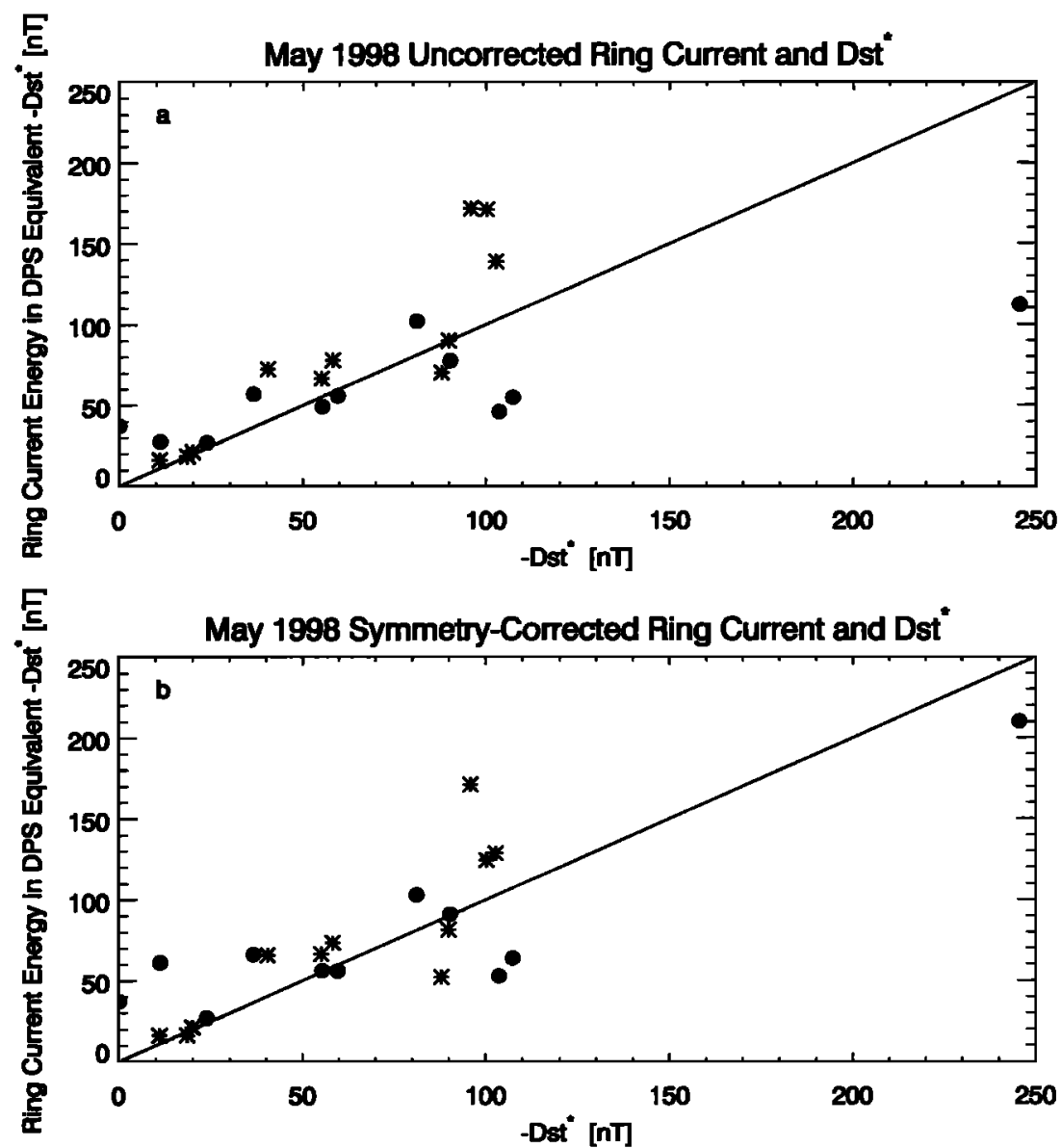

Figure 5. May 1998 storm event: Correlations between $D s t^{*}$ and measured ring current energy. (a) Not asymmetry corrected. (b) Asymmetry corrected. Filled circles indicate dayside passes (around 1000 MLT), and asterisks indicate nightside passes (around 2200 MLT).

which is accounted for by ring current ions and the standard deviation of same. Next are listed the correlations between the ring current and $D s t^{*}$ : first overall, then dayside (0600 $1800 \mathrm{MLT})$ and nightside ( 1800 - 0600 MLT) values.

This analysis shows that the ring current correlates more highly with $D s{ }^{*}$ for the nightside measurements, which is likely due to the fact that the ring current is injected on the nightside and incurs losses as particles drift around the Earth. The dayside values change less over a storm and contribute less to $D_{s t}{ }^{*}$. Also of note is that the standard deviations of these measurements are quite large. Again, this may be due partially to ring current asymmetry, since the measurements were taken at all local times and are therefore sampling all MLT sectors. The overall correlations are high but not overwhelming. This may also have to do with asymmetry. Additionally, the correlations get weaker as activity gets higher. This may be because of the increasing asymmetry during disturbed times as well as the smaller number of data points during peak activity periods. A scatterplot of all events in this study can be seen in Figure 6, which shows a moderately linear relationship between $D_{s t}$ and ring current energy.

Figure 7 shows ring current energy in units of equivalent $D s{ }^{*}$ divided by the actual $D s{ }^{*}$ for all events. The events are binned in order to better show the behavior as a function of activity. The line $Y=1$ shows the theoretical value: that is, it is the expected value if ground currents are $21 \%$ and tail currents are $25 \%$ of the measured Dst depression. Overall, the data fit well with the predicted values.

\section{Discussion and Conclusions}

\subsection{Electrons}

When estimating the energy deposited in the ring current, it would be useful to know the contribution of electrons to the total ring current energy. Unfortunately, studies of ring current electrons are not numerous. One study conducted by Frank [1967] found that up to $25 \%$ of the ring current energy could be due to electrons. No subsequent studies have confirmed this result. One of the authors (J. L. Roeder) conducted a recent study of ring current electrons with energies down to $20 \mathrm{keV}$ using the Imaging Electron Spectrometer (IES) and High Sensitivity Telescope (HIST) sensors on Polar. He found that less than $10 \%$ of the ring current energy could be attributed to electrons. However, the peak energy of ring current electrons is likely below this energy range, so it is still uncertain what the total contribution is. Realistic numbers regarding the amount of energy due to ring 


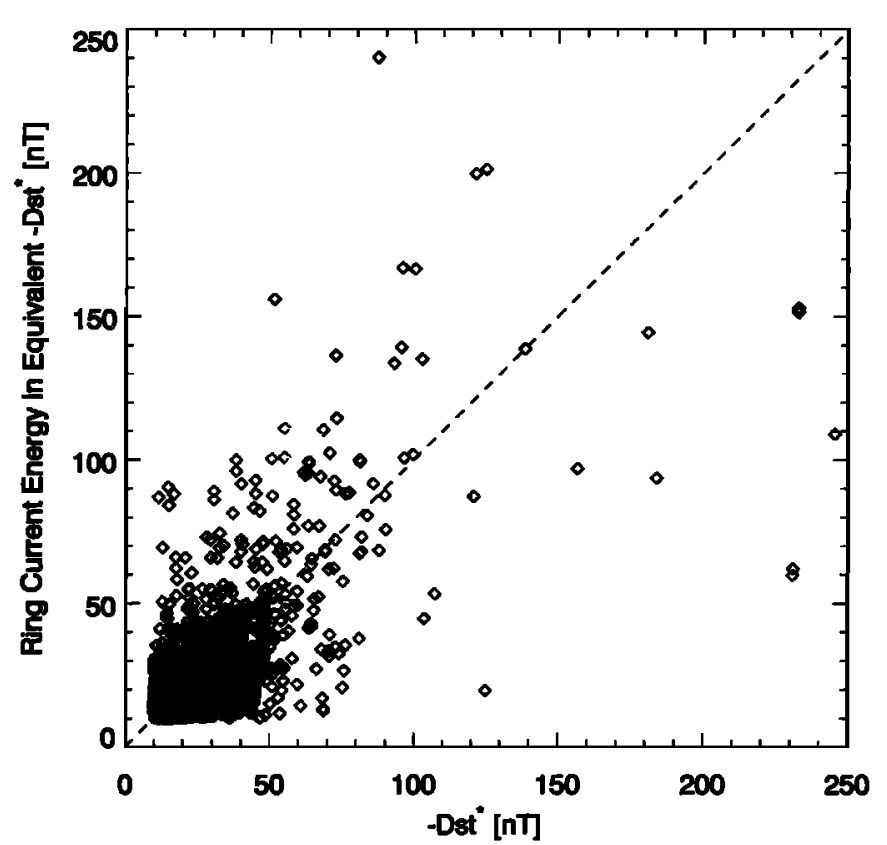

Figure 6. Correlation between $-D s t^{*}$ and measured ring current energy for March 1996 through September 1998. Ring current energy is in units of equivalent $-D s t^{*}$, meaning that the energy has been divided by the relevant constants in the DPS relation, including ground and tail corrections. The $\boldsymbol{Y}=\boldsymbol{X}$ line is shown to guide the eye.

current electrons would help refine our understanding of the ring current energy.

\subsection{Induction}

It is important to note that when we speak of the ring current contribution to $D s t$, we are strictly referring to the energy of the ring current particles. The ring current is known to play a role in inducing ground currents which influence Dst, but this contribution was separated out in this study. If one considers the indirect effects of the ring current, such as induced ground currents, in influencing Dst, then the contribution will be larger than that calculated in this paper.

\subsection{General Results}

Overall, the ring current data show good agreement with predicted values. The ring current energy contributes, on average, about $50 \%$ of the measured Dst depression for most events, which is well within statistical uncertainty of the predicted $54 \%$. There are clear trends of increasing asymmetry and weaker energy-Dst correlations during geomagnetically active times. The nightside dati correlate more highly with ground magnetometer traces than do the dayside measurements. Additionally, efforts to correct for azimuthal asymmetry proved fruitful: current models reproduce the asymmetry well, as evidenced in the May 1998 event. Other events were not as striking as this one, since it is rare to have a Polar pass through the ring current exactly at the peak of a storm, but they did show some improvement as well.

Interestingly, while the results for these storms agreed, on average, with theoretical predictions, individual storms var-

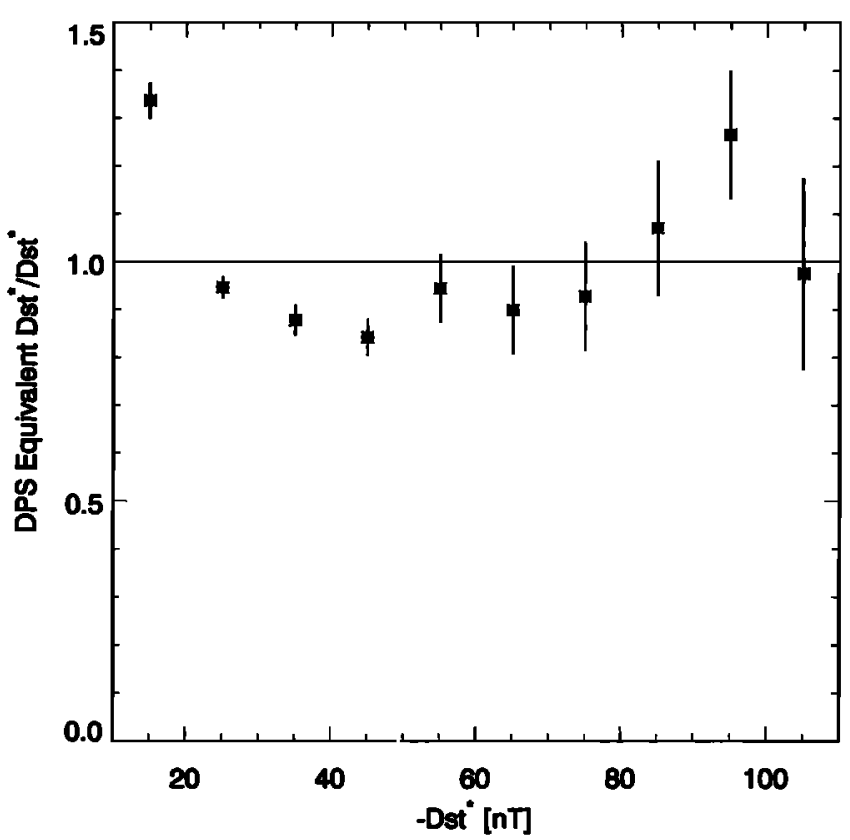

Figure 7. Relation between DPS relation data fit and - Dst* for March 1996 through September 1998. Ring current energy is converted to units of equivalent $D s t^{*}$, meaning that the energy has been divided by the relevant constants in the DPS relation, including ground and tail corrections, and then divided by $D s t^{*}$. Each bin has a width of $10 \mathrm{nT}$, and the error bars represent the standard deviation of the mean.

ied quite a lot. Certainly, some of this variation is due to ring current asymmetry - since most events were not asymmetry corrected, there are many cases of overestimating and underestimating the total particle energy simply due to the location of the satellite. However, as can be seen in Figure 2, there are excursions from the theoretical values in all MLT sectors and in both directions. It is not clear why these storms behave so differently. The standard deviations shown in Table 1 were large, around $25 \%$, suggesting that many events did not fit this model. Studying the differences in these events, using both magnetospheric and solar wind data, might shed some light on their different dynamics.

Acknowledgments. The work presented herein was supported by grants from the NASAVGS program and the Academy of Finland. The authors acknowledge H.B. Throop and P.R. Nelson for their contributions to this paper.

Janet G. Luhmann thanks Anders M. Jorgensen and T. Paul O'Brien for their assistance in evaluating this paper.

\section{References}

Arykov, A. A., and Y. P. Maltsev, Direct-driven mechanism for geomagnetic storms, Geophys. Res. Lett., 23, 1689-1692, 1996.

Baker, D. N., N. E. Turner, and T. I. Pulkkinen, Energy transport and dissipation in the magnetosphere during geomagnetic storms, J. Atmos. Sol. Terr. Phys., 63, 421 - 429, 2001.

Burton, R. K., R. L. McPherron, and C. T. Russell, An empirical relationship between interplanetary conditions and Dst, J. Geophys. Res., 80, 4204-4214, 1975.

Campbell, W. H., Geomagnetic storms, the Dst ring current myth 
and lognormal distributions, J. Atmos. Sol. Terr. Phys., 58, 1171$1187,1996$.

Daglis, I. A., R. M. Thorne, W. Baumjohann, and S. Orsini, The terrestrial ring current: Origin, formation, and decay, Rev. Geophys., 37, 407-438, 1999.

Dessler, A. J., and E. N. Parker, Hydromagnetic theory of magnetic storms, J. Geophys. Res., 64, 2239-2259, 1959.

Frank. L. A., On the extraterrestrial ring current during geomagnetic storms, J. Geophys. Res., 72, 3753-3768, 1967.

Greenspan, M. E., and D. C. Hamilton, A test of the Dessler-ParkerSckopke relation during magnetic storms, J. Geophys. Res., 105, 5419-5430, 2000.

Hamilton, D. C., G. Gloeckler, F. M. Ipavich, W. Studemann, B. Wilken, and G. Kremser, Ring current development during the great geomagnetic storm of February 1986, J. Geophys. Res., 93, 14,343-14,355, 1988.

Jordanova, V. K., C. J. Farrugia, J. M. Quinn, R. M. Thorne, K. W. Ogilvie, R. P. Lepping, G. Lu, A. J. Lazarus, M. F. Thomsen, and R. D. Belian, Effect of wave-particle interactions on ring current evolution for January 10-11, 1997: Initial results, Geophys. Res. Lett., 25, 2971-2974, 1998a.

Jordanova, V. K., C. J. Farrugia, L. Janoo, J. M. Quinn, R. B. Torbert, K. W. Ogilvie, R. P. Lepping, J. T. Steinberg, D. J. McComas, and R. D. Belian, October 1995 magnetic cloud and accompanying storm activity: Ring current evolution, J. Geophys. Res., 103, 79-92, 1998b.

Kozyra, J. U., V. K. Jordanova, R. B. Horne, and R. M. Thorne, Modeling of the contribution of electromagnetic cyclotron (EMIC) waves to stormtime ring current erosion, in Magnetic Storms, Geophys. Monogr. Ser., vol. 98, edited by B. T. Tsurutani et al., pp. 187-202, AGU, Washington, D. C., 1997.

Langel, R. A., and R. H. Estes, Large-scale, near-field magnetic fields from external sources and the corresponding induced internal field, J. Geophys. Res., 90, 2487-2494, 1985.
Lyons, L. R. and D. J. Williams, Quantitative Aspects of Magnetospheric Physics, 231 pp., D. Reidel, Norwell, Mass., 1984.

O'Brien, T. P., and R. L. McPherron, An empirical phase space analysis of ring current dynamics: Solar wind control of injection and decay, J. Geophys. Res., 105, 7707-7719, 2000.

Roeder, J. L., J. F. Fennell, M. W. Chen, M. Schultz, M. Grande, and S. Livi, CRRES observations of the composition of ring current populations, Adv. Space Res., 17, pp. (10)17 - (10)24, 1996.

Sckopke, N., A general relation between the energy of trapped particles and the disturbance field near the Earth, J. Geophys Res. 71, 3125-3130, 1966.

Turner, N. E., D. N. Baker, T. I. Pulkkinen, and R. L. McPherron, Evaluation of the tail current contribution to Dst, J. Geophys. Res., 105, 5431-5439, 2000.

Wilken, B., W. Weiss, D. Hall, M. Grande, F. Soraas, and J. F. Fennell, Magnetospheric ion composition spectrometer onboard the CRRES spacecraft, J. Spacecr. Rockets, 29, 585-591, 1992.

T. I. Pulkkinen and N. E. Turner, Finnish Meteorological Institute, Vuorikatu 15 A, P.O. Box 503, FIN-00101 Helsinki, Finland. (Niescja.Turner@fmi.fi)

D. N. Baker, Laboratory for Atmospheric and Space Physics, CB 590, University of Colorado at Boulder, Boulder, CO 80309-0590.

J. F. Fennell and J. L. Roeder, Aerospace Corporation, PO Box 92957 MS 260, Los Angeles, CA 90009.

V. K. Jordanova, Space Science Center, University of New Hampshire, Durham, NH 03824.

(Received May 3, 2000; revised February 12, 2001; accepted February 12, 2001.) 